\title{
Les Pitt. L'Angleterre face à la France 1708-1806
}

\section{Marc Belissa}

\section{(2) OpenEdition}

\section{Journals}

Édition électronique

URL : https://journals.openedition.org/ahrf/8073

DOI : 10.4000/ahrf.8073

ISSN : 1952-403X

\section{Éditeur :}

Armand Colin, Société des études robespierristes

\section{Édition imprimée}

Date de publication : 1 décembre 2006

Pagination : 201-203

ISSN : 0003-4436

\section{Référence électronique}

Marc Belissa, «Les Pitt. L'Angleterre face à la France 1708-1806», Annales historiques de la Révolution française [En ligne], 346 | Octobre/Décembre 2006, mis en ligne le 10 juillet 2008, consulté le 24 avril 2022. URL : http://journals.openedition.org/ahrf/8073 ; DOI : https://doi.org/10.4000/ahrf.8073

Ce document a été généré automatiquement le 24 avril 2022.

Tous droits réservés 


\title{
Les Pitt. L'Angleterre face à la France 1708-1806
}

\author{
Marc Belissa
}

\section{RÉFÉRENCE}

Edmond Dziembowski, Les Pitt. L'Angleterre face à la France 1708-1806, Paris, Perrin, 2006, 579 p., ISBN 2-262-01381-0, $25 €$.

1 L'ouvrage d'Edmond Dziembowski vient heureusement combler un vide de l'historiographie en langue française sur l'Angleterre. En effet, les ouvrages sur les deux Pitt dans notre langue sont peu nombreux, ils sont surtout très anciens. Les deux personnages sont en revanche particulièrement présents dans l'historiographie anglaise récente, comme en témoignent les ouvrages de Jennifer Mori, de Jeremy Black ou de Eric Evans par exemple. Le livre d'Edmond Dziembowski donne aux lecteurs français une synthèse utile et bienvenue de ces travaux anglais, mais il ne se limite pas à cette synthèse et utilise les sources diplomatiques françaises pour donner un angle de vue étranger - et moins partial - sur ces deux figures « héroïques » et « nationales » par excellence.

2 Le projet est original à trois titres. Tout d'abord, Edmond Dziembowski entend faire une double biographie qui ne soit pas une simple juxtaposition, mais un récit continu des événements politiques internes et externes à l'Angleterre dans sa relation conflictuelle avec la France (d'où le sous-titre "L'Angleterre face à la France 1708-1806»). Cette biographie de deux hommes si différents et pourtant si semblables se veut également comparative. En effet, les liens unissant le Premier et le Second William Pitt sont multiples: la répétition apparente des événements (un ministre s'appuie par deux fois sur la «nation " pour arriver au pouvoir et remet sa démission en pleine guerre, puis revient au pouvoir comme homme providentiel), la filiation idéologique (le « patriotisme » anglais) et enfin la dimension symbolique et personnelle (le « vrai » Pitt se cache derrière une statue du Commandeur politique). Enfin, et c'est 
peut-être l'aspect le plus original du projet, mais qui ne se fait jour qu'à la fin du livre, l'auteur entend faire la biographie d'un personnage imaginaire: le William Pitt, la figure nationale, synthèse et représentation politiques des deux William Pitt réels, l'ancien et le jeune, comme si de ces deux individus naissait une icône "nationale » unique.

3 La facture de l'ouvrage est classique, peut-être trop dans sa première partie, comme si le personnage du Premier Pitt se prêtait moins aux approches nouvelles de l'histoire politique que celui du Second Pitt. Edmond Dziembowski fait donc ici l'histoire politique des luttes de pouvoirs parmi les dirigeants whigs à partir du "règne » de Walpole. Cette histoire complexe, faite de revirements, de coups bas, de coups de partis et de coups d'éclat nous donne à voir la réalité des affrontements au sein du "petit monde » des oligarques de l'Angleterre georgienne. On pourra reprocher à cette vision de la politique anglaise un manque de recul et une vue presque exclusivement « d'en haut ", mais il est vrai que la "politique» parlementaire est alors l'affaire quasi personnelle de quelques centaines d'individus.

Dans sa première partie, Edmond Dziembowski insiste sur le "positionnement" politique du Premier Pitt, qui fonde sa carrière sur une posture d'opposant: tout d'abord opposant à l'oligarchie whig (à laquelle il est pourtant apparenté, notamment par la famille Grenville), puis au grand oligarque Walpole, et enfin à la prérogative de Georges II. Edmond Dziembowski met en valeur la filiation intellectuelle et philosophique du «patriotisme » de Pitt avec le républicanisme néoharringtonien des Commonwealthmen, mais aussi avec le torysme "renouvelé » par Bolingbroke dans son Idea of a Patriot King. La position spécifique du Premier Pitt dans le jeu politique anglais est qu'il entend s'appuyer sur le "peuple" extraparlementaire pour imposer une politique de puissance nationale contre le roi hanovrien. Sa violence oratoire, sa raideur, sa dureté légendaire dessinent une figure assumée et voulue de " républicain » à l'antique se battant contre la corruption des temps modernes, de Great Commoner incarnant la nation, de ministre de guerre tenant le gouvernail dans la tempête de la guerre de Sept Ans. On pourrait d'ailleurs s'interroger plus avant sur la fonction de cette image dans la carrière de Pitt. Instrumentalisation du "patriotisme » et du langage républicain? Manipulation? Construction voulue d'une image "décalée »? Il est bien difficile de faire la part du psychologique et du politique dans une telle attitude. En continuité avec ses travaux antérieurs, Edmond Dziembowski remarque que les années 1750-1760 voient l'émergence d'une nouvelle culture politique du patriotisme en Angleterre, avec la résurgence des débats sur la milice, sur la critique des mœurs despotiques à la française, avec la réhabilitation partielle des tories. De ce point de vue, «la phraséologie pittite s'inscrivait de manière idéale dans le climat intellectuel et moral de ces années de guerre» (p. 138). Il est certain néanmoins que cette phraséologie contraste avec une politique réelle bien plus pragmatique et moins dérangeante pour l'oligarchie whig qu'elle ne le prétend, surtout après son retour aux affaires.

5 Sans doute, une biographie de ce type n'est pas forcément le lieu de longs développements sur les concepts du langage politique, mais l'auteur nous laisse parfois un peu sur notre faim en utilisant sans plus d'explications des expressions comme la « voix de la nation » (p. 178) ou encore en décrivant de manière anachronique la prose de Wilkes comme des attaques au « lourd parfum populiste » (p. 172). Le « patriotisme » des deux Pitt aurait sans doute gagné à être comparé au patriotisme cosmopolitique 
défendu par d'autres courants des Lumières, car, comme l'ont bien compris les contemporains d'ailleurs, les deux hommes ont toujours pensé le "patriotisme" anglais comme l'idéologie de la construction d'une puissance nationale exclusive.

6 La deuxième partie sur William Pitt le jeune est plus enlevée. L'auteur y décrit l'ascension d'un jeune homme de vingt-quatre ans seulement qui accède au pouvoir, portant sur ses épaules l'héritage politique de son père. Celui qui est appelé aux affaires par Georges III n'est pas seulement William Pitt le jeune, mais surtout William Pitt tout court, la figure héroïque nationale imaginaire. Les points communs apparents entre le père et le fils sont nombreux, d'autant que l'héritier a vite compris l'intérêt politique de se couler dans le moule paternel et de revendiquer une image aussi hautaine et glaciale que celle du père était hautaine et volcanique. Orateur moins doué, il est certainement plus qualifié que son prédécesseur dans les questions financières et diplomatiques. C'est également un homme plus marqué par le réformisme des Lumières. Mais son réformisme est l'histoire d'un échec quasi-permanent: ni ses projets de (timide) réforme parlementaire, ni les assouplissements qu'il propose pour les minorités religieuses, ni les améliorations prévues pour l'Irlande n'aboutissent. Seul son projet d'abolition de la traite des esclaves (mais pas de l'esclavage) connait tardivement le succès.

7 Sans doute biaisée par le penchant naturel du biographe pour son objet d'étude, l'approche d'Edmond Dziembowski a peut-être tendance à dédouaner un peu trop le ministre de ces échecs faisant porter leur responsabilité à Georges III (il est vrai particulièrement arc-bouté sur ces trois sujets) ou à la « nation politique » trop tournée vers le passé pour accepter ces audaces (p. 298). On pourrait tout aussi bien accuser la pusillanimité d'un ministre qui a toujours cherché le compromis avec les oligarchies plutôt que l'affrontement. Pitt me semble ainsi emblématique de ces réformateurs éclairés, effrayés par la Révolution française et devenant nolens volens contrerévolutionnaires de fait, sinon de principes. Car si Pitt est peu inquiet jusqu'à la fin de 1792, il s'engage résolument par la suite dans une lutte à outrance contre la République française à l'extérieur et contre toute idée de réforme politique ou sociale à l'intérieur. Certes, Pitt n'est pas un partisan des Anti-Lumières ni un ami de Burke et quand il pense pouvoir discuter avec la République directoriale, il est ouvert à des négociations, mais Pitt n'a pas choisi la répression politique à contrecœur. Il est viscéralement et profondément antidémocrate.

8 Dans le louable souci de dédiaboliser la figure de Pitt "ennemi du genre humain ", Edmond Dziembowski a parfois tendance, selon moi, à tordre le bâton dans l'autre sens et à oublier que pour les contemporains (et pas seulement pour les Français) sa conduite de la guerre était absolument contraire aux principes les plus élémentaire du droit des gens : les orders in council de 1793 qui assimilent le ravitaillement alimentaire à de la contrebande et tentent d'affamer la population française, la fabrication des faux assignats, le massacre des marins français dans le port neutre de Gênes, etc., autant d'actes scandaleux pour les contemporains et assumés par la nécessité de la bellum internecinum (guerre d'extermination ou à outrance) contre les républicains français. L'Alien Bill, la suspension de l'Habeas Corpus, les Gagging Acts, la répression sanglante et féroce du général Lake en Irlande en 1798, ne sont pas moins à mettre à son " crédit " personnel. De même, y a-t-il peut être un certain angélisme à voir dans le rejet de Pitt de la Déclaration des droits de l'homme la conséquence de son non-respect supposé par les dirigeants français. Pitt, comme Burke, considérait que l'idée de la déclaration du 
droit naturel était en soi un acte "d'anarchie » s'attaquant à la société fondée sur la propriété et la religion. Pour ma part, je pense que Pitt n'est pas devenu contrerévolutionnaire par accident, mais par conviction antidémocrate.

9 Son image change dans la lutte contre Bonaparte puis Napoléon. Comme son père, il revient aux affaires après avoir démissionné et il apparaît alors comme l'homme providentiel dans le combat contre Napoléon. Son image aurait pu être écornée par Austerlitz, mais Trafalgar, puis sa fin prématurée, ont redonné au ministre l'aura du ministre combattant et vainqueur, puis mort à son poste pour l'Angleterre, à l'image de Nelson. Les deux morts participent d'une même mise en scène politique du service de la « nation » par les élites anglaises.

10 Les deux Pitt sont bien des personnages incontournables de l'histoire des relations franco-anglaises et l'un des grands mérites de cette belle « duo-biographie » est de nous en convaincre. 